\title{
HIPERGLIKEMIA SEBAGAI PREDIKTOR KEBERHASILAN PENGOBATAN PASIEN DENGAN SINDROM KORONER AKUT DI RSUD X SURAKARTA
}

\author{
HYPERGLICEMIA AS CLINICAL OUTCOME PREDICTOR \\ PATIENT WITH ACUTE CORONARY SYNDROME \\ IN RSUD X SURAKARTA
}

\begin{abstract}
Iin Novita Nurhidayati Mahmuda, Yuniana Nur Rezki, Wildan Priscillah
Program Studi Pendidikan Dokter, Fakultas Kedokteran Universitas Muhammadiyah Surakarta Korespondensi: dr. Iin Novita Nurhidayati Mahmuda, Sp. PD, M. Sc. Email: iin_novita@ums.ac.id
\end{abstract}

\begin{abstract}
ABSTRAK
Sindrom Koroner Akut atau acute coronary syndrome (ACS) dengan hiperglikemia pada saat masuk memiliki rerata mortalitas yang lebih tinggi, pada penelitian terbaru. Hiperglikemia pada pasien dengan ACS digambarkan sebagai respon akut dari keadaan hiperadrenergik dengan peningkatan risiko trombosis, sehingga bisa memperburuk kondisi pasien ACS selama dirawat di rumah sakit. Tujuan penelitian ini untuk mengetahui perbedaan lama tinggal dan mortalitas pada pasien ACS dengan stres hiperglikemia dan tanpa hiperglikemia stres. Jenis penelitian ini adalah penelitian observasional analitik dengan pendekatan cross sectional. Subjek penelitian adalah pasien ACS non-diabetes di RSUD X Surakarta. Data diperoleh dari rekam medis dengan teknik purposive sampling, dianalisis dengan uji Mann-Whitney. Subjek penelitian sebanyak 68 pasien, 34 pasien ACS dengan hiperglikemia dan 34 pasien ACS tanpa hiperglikemia. Hasil penelitian ini menyatakan ada perbedaan durasi lama tinggal pasien ACS dengan dan tanpa hiperglikemia $(p=0,002)$ dan tidak ada perbedaan rerata mortalitas diantara keduanya.
\end{abstract}

Kata kunci: Sindrom Koroner Akut, Hiperglikemia, Lama Rawat Inap, Mortalitas

ABSTRACT

Acute Coronary Syndrome (ACS) in recent studies has been associated with hyperglycemia at the time of admission with higher mortality rates. Hyperglycemia in patients with ACS described as an acute response from a hyperadrenergic state with an increased risk of thrombosis, so it could worsen the condition of the patient ACS during the hospital stay. Aims of this study are to know differences in length of stay and mortality in ACS patients with hyperglycemia stress and without hyperglycaemia stress. This was an analytical observational research design with cross sectional approach. The subjects were non diabetic ACS patient in RSUD X Surakarta. Data were obtained from medical record with purposive sampling technique, analyzed by Mann-Whitney test. Subjects were 68 patients, 34 patients ACS with hyperglycemia and 34 patients ACS without hyperglycemia. There is a difference in duration long of stay ACS patients with and without hyperglycemia $(p=0.002)$ and there is no difference in mortality.

Keywords: Acute Coronary Syndrome, Hyperglycemia, Length Of Hospitalization, Mortality

\section{PENDAHULUAN}

Penyakit Jantung Koroner (PJK) masih menjadi masalah kesehatan utama baik di negara maju maupun negara berkembang. Menurut data World Health Organization (WHO) tahun 2012, dari 17,5 juta kematian akibat penyakit tidak menular, terdapat 7,4 juta kematian akibat PJK, dan diperkirakan angka kematian ini akan terus meningkat hingga mencapai 23,3 juta kematian pada tahun 2030.

Data epidemiologi di Indonesia pada tahun 2013, berdasarkan diagnosis dokter menunjukkan prevalensi penderita PJK sebanyak $0,5 \%$ atau diperkirakan sekitar 883.447 kasus dari seluruh pasien penyakit tidak menular, dan untuk prevalensi PJK di Jawa Tengah sebesar 0,5\% 
atau sekitar 120.447 kasus (Riskesdas, 2013). Sementara Kota Surakarta menempati posisi tertinggi kedua di Jawa Tengah setelah Kabupaten Klaten yaitu sekitar 917 kasus (Depkes, 2014).

Sindrom Koroner Akut (SKA) merupakan bagian manifestasi klinis dari Penyakit Jantung Koroner (PJK) dan merupakan kegawatan jantung yang serius. Beberapa studi selama dekade terakhir ini telah menghubungkan hiperglikemia pada saat masuk rumah sakit dengan angka mortalitas yang cukup tinggi pada pasien dengan sindrom koroner akut (SKA), termasuk Infark Miokard Akut (IMA). Pada penderita infark miokard akut non diabetik dengan hiperglikemia pernah dilaporkan angka kematian rata-rata selama perawatan di rumah sakit sebesar $25 \%$, sedangkan yang tanpa hiperglikemia sebesar 6\% (Irawan, et al., 2005). Penelitian bagian unit kardiologi Universitas Indonesia di Rumah Sakit Jantung Harapan Kita Jakarta juga melaporkan bahwa stress hiperglikemia pada pasien infark miokard akut non-Diabetes Melitus (DM) meningkatkan risiko terjadinya gagal jantung dan kematian (Oktarina et al., 2013).

Hiperglikemia yang terjadi pada pasien Sindroma Koroner Akut (SKA) menggambarkan respon akut dari keadaan hiperadrenergik dengan peningkatan risiko thrombosis. Sehingga hiperglikemia tidak hanya dapat meningkatkan risiko terjadinya SKA, melainkan juga dapat memperburuk kondisi pasien SKA. Hal tersebut yang diduga juga mempengaruhi lama hari rawat pasien SKA baik secara langsung maupun tidak langsung selama masa perawatan di rumah sakit (Oktarina et al., 2013).

Dalam penelitian sebelumnya menghubungkan lama hari rawat inap pasien SKA non diabetik dengan kadar glukosa darah saat masuk rumah sakit, dimana diperoleh rerata lama hari rawat pasien jika kadar glukosa darah saat masuk rumah sakit sebesar $<140 \mathrm{mg} / \mathrm{dl}$ adalah 7,43 $\pm 2,152$ hari ( $\mathrm{n}=28$ ), sedangkan pasien dengan kadar glukosa darah saat masuk rumah sakit sebesar $140-199 \mathrm{mg} / \mathrm{dl}$ memiliki rerata lama hari rawat selama $6,94 \pm 2,536$ hari $(\mathrm{n}=17)$ (Oktarina, et al., 2013). Dengan demikian dapat dikatakan bahwa stres hiperglikemia memberikan efek yang lebih buruk terkait dengan lama rawat inap pada pasien SKA. Hal ini yang mendasari peneliti untuk melakukan penelitian tentang perbedaan lama rawat inap dan mortalitas pada pasien Sindrom Koroner Akut dengan stres hiperglikemia dan tanpa stres hiperglikemia non diabetik di RSUD X Surakarta.

\section{METODE}

Penelitian ini menggunakan desain penelitian observasional analitik dengan pendekatan secara cross sectional. Subjek penelitian diambil dengan purposive sampling dengan analisis Uji Mann Whitney. Penelitian ini dilakukan di bagian rekam medis RSUD X Surakarta pada November- Desember 2017. Populasi terjangkau adalah pasien Sindrom Koroner Akut (SKA) yang menjalani rawat inap di Unit Kardiologi dan Kedokteran Vaskuler di RSUD X Surakarta dan sesuai kriteria restriksi antara bulan Januari 2013 sampai Oktober 2016.

\section{HASIL DAN PEMBAHASAN}

Dalam pelaksanaan penelitian, penelusuran dimulai dengan mencari kode diagnosis ICD $\mathrm{X}$ pasien dengan sindrome koroner akut sesuai dengan periode waktu yang ditetapkan penelitian didapatkan 97 rekam medis. Setelah dilakukan pengambilan data secara seksama 68 subjek penelitian yang lengkap dan dapat dianalisis. Dari data tersebut terdapat 34 rekam medis pasien Sindrom Koroner Akut (SKA) dengan stres hiperglikemia non diabetik dan 34 rekam medis pasien Sindrom Koroner Akut (SKA) tanpa stres hiperglikemia non diabetik. 
Tabel 1. Distribusi Subjek Penelitian

\begin{tabular}{|c|c|c|c|c|}
\hline & Hiperglikemia & $\begin{array}{c}\text { Tanpa } \\
\text { Hiperglikemia }\end{array}$ & \multirow[t]{2}{*}{$p$} & \multirow[t]{2}{*}{ Total } \\
\hline & n (\%) & n (\%) & & \\
\hline \multicolumn{5}{|l|}{ Diagnosis } \\
\hline NSTEMI & $14(20.6 \%)$ & $13(19.1 \%)$ & \multirow[b]{3}{*}{0.011} & \\
\hline STEMI & $13(19.1 \%)$ & $4(5.9 \%)$ & & $\begin{array}{l}21 \\
17\end{array}$ \\
\hline UAP & $7(10.3 \%)$ & $17(25.0 \%)$ & & $\begin{array}{l}17 \\
24\end{array}$ \\
\hline \multicolumn{5}{|l|}{ Jenis Kelamin } \\
\hline Laki-laki & $21(30.9 \%)$ & $25(36.8 \%)$ & & 46 \\
\hline Perempuan & $13(19.1 \%)$ & $9(13.2 \%)$ & & $\begin{array}{l}40 \\
22\end{array}$ \\
\hline Tekanan Darah & & & \multirow{2}{*}{0.300} & \\
\hline Normal & $9(13.2 \%)$ & $9(13.2 \%)$ & & 18 \\
\hline Prehipertensi & $10(14.1 \%)$ & $13(19.1 \%)$ & \multirow{4}{*}{0.852} & $\begin{array}{l}18 \\
23\end{array}$ \\
\hline Hipertensi Tahap 1 & $8(11.8 \%)$ & $7(10.3 \%)$ & & 23 \\
\hline Hipertensi Tahap 2 & $7(10.3 \%)$ & $5(7.4 \%)$ & & 15 \\
\hline Rerata $\pm \mathrm{SD}(\mathrm{mmHg})$ & $134.82 \pm 27.16$ & $131.97 \pm 23.13$ & & 12 \\
\hline \multicolumn{5}{|l|}{ IMT } \\
\hline Gizi Kurang & $2(2.9 \%)$ & $2(2.9 \%)$ & \multirow{6}{*}{0.789} & \multirow{6}{*}{$\begin{array}{c}4 \\
32 \\
12 \\
16 \\
4\end{array}$} \\
\hline Gizi Normal & $17(25.0 \%)$ & $15(22.1 \%)$ & & \\
\hline Berisiko Obesitas & $5(7.4 \%)$ & $7(10.3 \%)$ & & \\
\hline Obesitas 1 & $9(13.2 \%)$ & $7(10.3 \%)$ & & \\
\hline Obesitas 2 & $1(1.5 \%)$ & $3(4.4 \%)$ & & \\
\hline $\operatorname{Rerata} \pm \mathrm{SD}\left(\mathrm{Kg} / \mathrm{m}^{2}\right)$ & $23.50 \pm 3.76$ & $23.85 \pm 3.84$ & & \\
\hline \multirow{2}{*}{$\begin{array}{l}\text { Outcome klinis } \\
\text { Hidup } \\
\text { Meninggal }\end{array}$} & $32(94 \%)$ & $32(94 \%)$ & \multirow{2}{*}{0.5} & \\
\hline & $2(6 \%)$ & $2(6 \%)$ & & \\
\hline
\end{tabular}

Tabel 2. Perbedaan Lama Rawat Inap Pasien SKA Dengan Stres Hiperglikemia Dan Tanpa Stres Hiperglikemia Non Diabetik.

\begin{tabular}{|c|c|c|c|c|}
\hline \multirow{3}{*}{ Gula Darah Sewaktu } & \multicolumn{2}{|c|}{ Lama Rawat Inap } & \multirow{2}{*}{ Total } & \multirow{3}{*}{$\begin{array}{c}\text { Rerata } \pm \text { SD } \\
\quad \text { (hari) }\end{array}$} \\
\hline & $\geq 7$ hari & $<7$ hari & & \\
\hline & $n(\%)$ & $n \%$ & $\mathbf{N}$ & \\
\hline Hiperglikemia & $14(20.6 \%)$ & $20(29.4 \%)$ & 34 & $6.18 \pm 3.12$ \\
\hline Tanpa Hiperglikemia & $2(2.9 \%)$ & $32(47.1 \%)$ & 34 & $4.15 \pm 1.42$ \\
\hline Jumlah & 16 & 52 & 68 & \\
\hline
\end{tabular}

Berdasarkan data pada tabel 3 di atas diketahui bahwa kelompok lama rawat inap $\geq 7$ hari dengan hiperglikemia berjumlah 14 (20.6\%) pasien yang lebih banyak dibandingkan dengan kelompok lama rawat inap $\geq 7$ hari tanpa hiperglikemia hanya sejumlah $2(2.9 \%)$ pasien saja. Sedangkan kelompok lama rawat inap $<7$ hari dengan hiperglikemia berjumlah 20 (29.4\%) pasien yang lebih sedikit dibandingkan dengan kelompok lama rawat inap $<7$ hari tanpa hiperglikemia yang berjumlah $32(47.1 \%)$ pasien.

Tabel 3. Rerata Usia Dengan Lama Rawat Inap Pasien SKA Dengan Stress Hiperglikemia Dan Tanpa Stress Hiperglikemia.

\begin{tabular}{cccc}
\hline & $\mathbf{N}$ & $\mathbf{\%}$ & Rerata \pm SD (tahun) \\
\hline$\geq 7$ hari & 16 & $23.5 \%$ & $54.44 \pm 6.30$ \\
$<7$ hari & 52 & $76.5 \%$ & $51.92 \pm 7.04$ \\
Jumlah & 78 & $100 \%$ & \\
\hline
\end{tabular}


Tabel 4. Uji Normalitas Data

\begin{tabular}{ccccc}
\hline & \multirow{2}{*}{ GDS } & \multicolumn{3}{c}{ Shapiro-Wilk } \\
\cline { 3 - 5 } & & Statistic & df & Sig. \\
\hline Lama Rawat Inap & Hiperglikemia & .888 & 34 & .002 \\
Tanpa Hiperglikemia & .925 & 34 & .023 & \\
\hline
\end{tabular}

Sehingga untuk uji beda tidak uji Mann-Whitney karena sebaran data tidak berpasangan menggunakan uji alternatif yaitu normal.

Tabel 5. Uji Mann-Whitney

\begin{tabular}{cccc}
\hline & N & $\begin{array}{c}\text { Median } \\
\text { (minimum-maksimum) }\end{array}$ & $\boldsymbol{p}$ \\
\hline Lama Rawat Inap dengan Hiperglikemia & 34 & $6(2-17)$ & 0.002 \\
Lama Rawat Inap tanpa Hiperglikemia & 34 & $4(2-8)$ & \\
\hline
\end{tabular}

Berdasarkan data pada tabel 6 Diperoleh nilai signifikansi ( $p=0.002$ ), karena nilai $\mathrm{p}<0.05$ secara statistik dapat disimpulkan bahwa terdapat perbedaan lama rawat inap pasien SKA dengan stres hiperglikemia dan tanpa stres hiperglikemia non diabetik.

Pada penelitian ini diketahui bahwa menurut diagnosisnya untuk pasien dengan hiperglikemia diperoleh jumlah lebih banyak yaitu dengan diagnosis NSTEMI sebesar 14 $(20.6 \%)$ pasien, sedangkan untuk pasien tanpa hiperglikemia yang memperoleh jumlah lebih banyak yaitu dengan diagnosis UAP sebesar $17(25.0 \%)$ pasien dan dengan nilai signifikansi $p=0.011$. Hasil ini tidak sesuai dengan penelitian sebelumnya yang menyebutkan untuk pasien SKA dengan hiperglikemia lebih banyak terdapat pada diagnosis STEMI yaitu terdapat 106 (59.9\%) pasien, sedangkan untuk NSTEMI dan UAP hanya memperoleh masing-masing 26 (14.7\%) dan 45 (25.4\%) pasien. Dan pada pasien SKA tanpa hiperglikemia lebih banyak terdapat pada diagnosis STEMI juga yaitu sebesar 51 (46.4\%) pasien dengan nilai $p=0.071$ (Mansour and Wanoose, 2011).

Hasil penelitian sebelumnya juga sesuai dengan penelitian yang dilakukan oleh Ishihara, et al., (2009) yang menyebutkan bahwa adanya suatu hubungan yang bermakna $(\mathrm{p}=<0,001)$ antara STEMI dengan kadar gula darah, terlihat pada STEMI paling banyak terdapat kelompok hiperglikemia. Pada penelitian Kolmam et al., (2009) juga mengungkapkan pada jenis SKA dengan tipe STEMI terdapat hubungan yang signifikan dengan kadar gula darah sedangkan pada jenis NSTEMI dan UAP tidak terdapat hubungan yang signifikan dengan kadar gula darah.

Secara teoritis menyebutkan peningkatan usia akan meningkatkan lama perawatan selama di rumah sakit serta meningkatkan kemungkinan terjadinya kematian PJK. Peningkatan usia menyebabkan perubahan anatomi dan fisiologik pada jantung manusia. Perubahan anatomi meliputi perubahan dinding media aorta, penurunan jumlah inti sel jaringan fibrosa stroma katup, penumpukan lipid, perubahan miokardium akibat proses penuaan yang klasik berupa "brown atrophy", penurunan berat jantung dan timbulnya lesi fibrotik diantara serat miokardium. Sedangkan perubahan fisiologik jantung berupa denyut jantung maksimum latihan menurun, isi semenit jantung (cardiac output) dan daya cadangan jantung menurun (Gobel dan Mahkota, 2006).

Meski seringkali terdapat aterosklerosis pada manula, secara normal pembuluh darah akan mengalami penurunan debit aliran akibat peningkatan situs deposisi lipid pada endotel. Lebih jauh, terdapat pula perubahan arteri koroner difus yang pada awalnya terjadi di arteri koroner kiri ketika muda, kemudian berlanjut pada arteri koroner kanan dan posterior di atas usia 60 tahun (Majid, 2010).

Pada kelompok lama rawat inap $\geq 7$ hari dengan hiperglikemia berjumlah 14 (20.6\%) pasien yang lebih banyak dibandingkan dengan kelompok lama rawat inap $\geq 7$ hari tanpa hiperglikemia 
hanya sejumlah $2(2.9 \%)$ pasien saja. Sedangkan kelompok lama rawat inap $<7$ hari dengan hiperglikemia berjumlah 20 (29.4\%) pasien yang lebih sedikit dibandingkan dengan kelompok lama rawat inap $<7$ hari tanpa hiperglikemia yang berjumlah $32(47.1 \%)$ pasien. Dengan rerata kelompok rawat inap disertai hiperglikemia sebesar $6.18 \pm 3.12$ hari sedangkan pada kelompok rawat inap tanpa disertai hiperglikemia selama $4.15 \pm 1.42$ hari, serta dengan menggunakan uji Mann-Whitney diperoleh nilai signifikansi ( $p=$ 0.002), karena nilai $\mathrm{p}<0.05$ secara statistik dapat disimpulkan bahwa terdapat perbedaan lama rawat inap pasien SKA dengan stres hiperglikemia dan tanpa stres hiperglikemia non diabetik.

Hasil tersebut sesuai dengan penelitian sebelumnya yang menyebutkan bahwa rerata kelompok lama rawat inap pada dengan hiperglikemia memiliki rerata $9.0 \pm 0.7$ hari sedangkan untuk rerata kelompok rawat inap tanpa disertai hiperglikemia dijumpai rerata selama $4.5 \pm 0.1$ hari (Guillermo, et al., 2002). Namun pada penelitian sebelumnya menurut Oktarina., (2013) memiliki hasil yang sedikit berbeda dimana rerata kelompok lama rawat inap pasien SKA dengan hiperglikemia sebesar $6.94 \pm 2.54$ hari sedangkan untuk kelompok lama rawat inap pasien SKA tanpa hiperglikemia memiliki rerata $7.43 \pm 2.15$ hari.

Sedangkan untuk angka mortalitas pasien dengan atau tanpa hiperglikemia tidak didapatkan perbedaan yang signifikan. Pasien dengan hiperglikemia meninggal sebanyak 2 orang dan pasien tanpa hiperglikemia meninggal sebanyak 2 orang. Hal ini kemungkinan disebabkan karena faktor mortalitas pada pasien PJK dipengaruhi oleh komorbid yang ada seperti diabetes, hipertensi yang tidak terkontrol, usia dan komorbid lain yang belum dipertimbangkan dalam analisis penelitian ini.

Pada penelitian ini masih terdapat beberapa kelemahan, meskipun hasil hipotesis sesuai dengan yang diharapkan. Kelemahan dalam penelitan ini yaitu dilakukan dengan menggunakan metode cross sectional, dimana faktor resiko dan efek hanya diamati dalam satu waktu saja sehingga tidak menggambarkan hubungan sebabakibat yang kuat. Design penelitian yang lebih tepat adalah case control. Design penelitian ini belum dapat dilakukan karena rekam medis yang diberikan terbatas jumlah dan waktu pencatatan sesuai tanggal yang ditetapkan bagian rekam medis RSUD X Surakarta. Kelemahan lain dari penelitian ini dikarenakan jumlah minimal sampel penelitian tidak memenuhi sampel size dikarenakan beberapa subjek penelitian harus diekslusikan karena terdapat data-data ekstrem dan adanya kemungkinan diagnosis tambahan yang mungkin diderita pasien tetapi tidak tertulis secara eskplisit pada rekam medis. Kelemahan ketiga adalah pengukuran kadar glukosa darah yang digunakan hanya menggunakan kadar glukosa darah sewaktu sehingga tidak bisa mengetahui dengan pasti riwayat hiperglikemia pada pasien

\section{SIMPULAN}

Berdasarkan hasil penelitian, dapat ditarik kesimpulan bahwa terdapat perbedaan lama rawat inap pasien Sindrom Koroner Akut dengan stres hiperglikemia dan tanpa stres hiperglikemia non diabetik di RSUD X Surakarta.

\section{DAFTAR PUSTAKA}

Depkes (Departemen Kesehatan)., 2014. Profil Kesehatan Provinsi Jawa Tengah Tahun2014.http://www. depkes.go.id/resources/download/profil/PROFIL_KES_PROVINSI_2014/13_Jateng_2014.pdf [diakses tanggal 22 Maret 2016]

Gobel, F.A. dan Mahkota, R., 2006. Faktor-faktor yang Mempengaruhi Kematian Pasien Penyakit Jantung Koroner di Pusat Jantung Nasional Harapan Kita Tahun 2004. Jakarta: Jurnal Kesehatan Masyarakat Nasional Vol. 1, No. 3, Desember 2006.

Guillermo, E.. Umpierrez, S.D., Isaacs., Niloofar B., Xiangdong Y., Leonard, M.T., dan Abbas, E.K. 2002. Hyperglycemia: An Independent Marker of In-Hospital Mortality in Patients with Undiagnosed Diabetes. J Clin Endocrinol Metab, 87(3):978-982.

Irawan, B., Rochmah, W., Suharno., 2005. Hubungan Kadar Gula Darah Saat Masuk Rumah Sakit 
Dengan Cardiac Event Pada Penderita Infark Miokard Akut Di RS Dr. Sardjito. Junal Kedokteran Brawijaya, Vol. XXI, No.1.

Ishihara, M., Kojima, S., Sakamoto, T., Kimura, K., Kosuge, M., Asada, Y., et al. 2009. Comparison of blood glucose values on admission for acute myocardial infarction in patients with versus without diabetes mellitus. Am J Cardiol.104:769-74.

Kolmam, L., Yu-Chen, H., Montgomery., Gordon, K., Eagle, K.A., Jackson, et al. Prognostic value of admisson fasting glucose levels in patients with acute coronary syndrom. Am J Cardiol. 2009;104: 470-4.

Majid, A., 2010. Analisis Faktor-Faktor Yang Berhubungan Dengan Kejadian Rawat Inap Ulang Pasien Gagal Jantung Kongestif Di Rumah Sakit Yogyakarta Tahun 2010. Jakarta.

Mansour, A.A. and Wanoose, H.L. 2011. Acute Phase Hyperglycemia Among Patients Hospitalized with Acute Coronary Syndrome: Prevalence and Prognostic Significance. Oman Medical Journal. Vol 26, No.2:85-90

Oktarina, R., Karani, Y., Edward, Z., 2013. Hubungan Kadar Glukosa Darah Saat Masuk Rumah Sakit Dengan Lama Hari Rawat Pasien Sindrom Koroner Akut (SKA) Di RSUP Dr.M. Djamil Padang. Padang: Jurnal Kesehatan Andalas, 2(2).

RISKESDAS (Riset Kesehatan Dasar)., 2013. Badan Penelitian dan Pengembangan Kesehatan Kementerian Kesehatan. Depkes RI. Jakarta. http://www.depkes.go.id/download. php?file=download/pusdatin/infodatin/infodatin-jantung.pdf [diakses tanggal 22 Maret 2016]

WHO (World Health Organization)., 2012. Media Centre. Non-communicable diseases. http://www. who.int/mediacentre/factsheets/fs355/en/ [diakses tanggal 15 Maret 2016] 